\section{Benford's Law and transparency: an analysis of municipal expenditure}

\author{
Ricardo Sartori Cella ${ }^{\dagger}$ \\ Universidade Federal de Goiás, Goiânia, GO, Brazil \\ Ercilio Zanolla ${ }^{\Omega}$ \\ Universidade Federal de Goiás, Goiânia, GO, Brazil
}

\section{ABSTRACT}

This study aims to ascertain an adherence between the level of municipal transparency and the application of Benford's Law in implementing the municipal expenditure. Therefore, two municipalities in the state of Goiás were selected, one with a higher and one a lower level of transparency, according to the National Transparency Ranking of the Federal Public Ministry, of 2016. Then, we performed $\mathrm{Z}$ and chi-square tests on the expenses engaged in the first four months of 2016 to check for incompliances with the Benford's Law. Based on the data analyzed we were able to conclude that: the municipality with greater transparency has greater conformity with Benford's Law; the municipality with less transparency showed greatest discrepancies between the expected and observed frequencies; the municipality with less transparency showed higher likelihood of irregularities in the execution of expenditures, compared to the municipality with greater transparency. Both municipalities showed discrepancies regarding Benford's Law, differing from each other only by the degree of calculated divergences from the model.

Keywords: Data Auditing; Ranking of Municipal Transparency; Accounting Fraud Detection; Municipal Expenditures; Corruption.

\section{INTRODUCTION}

The evolution of information technology has made the volume and variety of information grow rapidly in recent years. Nowadays, the traditional financial analysis methods should evolve; so that accounting could timely update all companies' transactions and give useful information for decision-making. These analytical techniques, which involved statistics, made the work of auditors simpler and more effective, and contributed to identify the operational discrepancies and frauds in auditing (DURTSCHI; HILLISON; PACINI, 2004).

Considering that discrepancies in accounting numbers related to a pre-defined standard could be a fraud indicative, this study aims to perform an exploratory analysis regarding the relationship between conformity standards of public expenditure values and the degree of the municipality's transparency. Therefore, the objective of this study is to verify whether the conformity of public expenditures with Benford's Law (BL) relates to municipal transparency level, comparing two municipalities, one with greater and one with less transparency.
Corresponding author:

† Universidade Federal de Goiás, Goiânia, GO, Brazil E-mail: ricardosartoricella@gmail.com

$\Omega^{\Omega}$ Universidade Federal de Goiás, Goiânia, GO, Brazil E-mail: erciliozanolla@hotmail.com

Received: $11 / 23 / 2016$ Revised: $02 / 03 / 2017$.

Accepted: 12/11/2017

Published Online: 06/25/2018.

DOI: http://dx.doi.org/10.15728/bbr.2018.15.4.2 
Other studies, mainly since the 1980s, used Benford's Law in the area of finance and government auditing, such as: Carslaw (1988), Durtschi, Hillison and Pacini (2004), Nigrini (2005), Santos, Diniz and Corrar (2005), Krakar and Zgela (2009), Costa, Santos and Travassos (2012), Cunha and Bugarin (2015). However, none of them considered the probabilistic model with a municipal transparency ranking. Therefore, the importance of this study is to demonstrate that digital analysis through predictive irregularity models applied to accounting information, especially in Public Administration, could be useful not only for detecting evidence of fraud and corruption, but also for qualifying the transparency from a determined public entity.

Therefore, we used the probabilistic model, known as Benford's Law, which was originally presented in 1881 (NEWCOMB, 1881; DURTSCHI; HILLISON; PACINI, 2004) and publicly widespread since a study conducted by Frank Benford in 1938, due to its wide applicability (BENFORD, 1938; COSTA; TRAVASSOS; SANTOS, 2013). For this purpose, we analyzed 3,068 expenditures in two municipalities from the State of Goiás, one with greater and one with less transparency, from January to April, 2016. As a parameter of transparency, we adopted the national transparency ranking (MPF, 2016). We measured the degree of compliance with Benford's Law through $\mathrm{Z}$ and chi squared statistical tests, applied to the first and second digits of the contracts issued by the two municipalities.

Results indicate that the greater transparent municipality showed higher conformity with Benford's Law, when compared to the less transparent one. In short, there is a discrepancy in observed and expected frequencies in less transparent municipality expenses. Through this study, we are able to demonstrate that the use of analytical techniques can contribute to the social control in monitoring public expenses and in combating corruption. Because Benford's Law could show, for example, that something wrong may be happening in the management of public expenditure, but at the same time, the manager does not want to give the necessary transparency. Besides that, we were also able to contribute to filling a gap unexplored by other researchers, making a way to new studies with a higher number of federal entities.

\section{LITERATURE REVIEW}

\subsection{Agency Theory in the Public Administration context}

We can analyze the government interaction with several agents from the perspective of the Agency Theory. The Agency Theory has been one of the most important theoretical models in Accountancy over the last 25 years, (LAMBERT, 2007). According to the author, the Agency Theory addresses the relationship between the principal and the agent, and its respective relationship conflicts inside the organizational environment. In this scenario, the principal hires the agent to make operational, investment and financial decisions and to take the risks, with the purpose of achieving the objectives of the principal, through the delegation of power.

In the agency theory perspective, the agency may be governed by contracts between agents and principals, but these actors have different interests (JENSEN; MECKLING, 1976).

The authors state that to avoid agents acting in dissonancy to principal interests, they have to bear with agency costs, represented by controlling and monitoring systems, assures grants and also by residual costs, in order to ensure contractual equilibrium.

Considering that in an authority delegation process, the individuals share risks, an unbalance arises considering the results distribution in relation to assumed risk in the contract, resulting from the actions/decisions of individuals (HOLMSTROM, 1979). 
Agent behavior is rational in its nature and individualist at the same time, because they make decisions amongst several alternatives based on the goal of maximizing the personal interest, to the detriment of the principal. As a result, the agency conflict shows up, which results from factors such as aversion to effort, the diversion of resources to their own advantage, lack of concern about the future in the company and different levels of risk aversion (LAMBERT, 2007).

Holmstrom (1979) reveals that the consequence of opportunist behavior is the moral risk that is a negative influence variable for a great correspondence relationship between the agent financial incentive and the decision made to maximize principal interests. The origin of moral risk is associated to informational asymmetry that results from individual actions that we cannot monitor in an environment where one of the parts, has superior information in relation to the other (AKERLOF, 1970; HOLMSTROM, 1979).

As a way to reduce informational asymmetry, Holmstrom (1979) emphasizes the role of management accounting; however, he does not detach the contracts renegotiation possibility, inside certain limits, as a remedy to correct problems associated to agent behavior, seeking the promotion of benefits for both parts.

For Lambert (2007), the prominent position where the agent is, assures the access to privilege information, which allows increasing its personal gains, mainly because their intention to stay in the company is less by the part of the agent than the principal is, so it is necessary to maximize their personal interest in a short period.

According to Baker, Jensen and Murphy (1988), contractual rules can influence the behavior inside an organization. This way, the existence of compensation and incentives for performance systems can be helpful in motivating the agents. This organizational policy can be associated to a firm compensation policy with bonuses and divisional profits, as an incentive to merit promotion and additional benefits, glimpsing the construction of a solid career.

However, the problem of creating incentives for agents is much more complex than the approach through the principal-agent model (HOLMSTROM; MILGROM, 1991). For example, in public administration, contracts are short-term, four years on average, and variable compensation that could encourage the agent's behavior is not always possible. The political agent, therefore, cannot be financially rewarded by their merit, except for society's recognition. Depending on ethical values formation, this agent would seek other ways to compensate their financial gain by seeking illicit alternatives associated with corruption to satisfy their personal interests.

Fundenberg, Holmstrom and Milgrom (1990) point that short-term contracts are sufficient to support effective systems; however only long-term contracts can avoid rehires in an environment of informational asymmetry. Therefore, public administration faces a dilemma, because the agent contracts are short-term, but they would need additional incentives that only long-term contracting provides.

Considering the entire problematic showed, it also important to mention the study carried out by Cressey (1953), which reports that some managers, in taking advantage of their technical skills, their strategic position in the organization and by being pressured by financial hardships, envision an opportunity to commit fraud, in order to temporarily solve their problems, although they end up accepting the fact as a rational and justifiable attitude.

The theory known as the Fraud Triangle consists of three pillars or vertices: pressure, opportunity and rationalization (CHOO; TAN, 2007). Pressure is something that happened in the personal life of the fraudster and generates a stressful need that forces them to defraud. Opportunity suggests that fraudsters have the business knowledge and perceive this as an opportunity to commit fraud. Finally, rationalization is a process in which an employee or 
fraudster conditions themselves to accept fraudulent behavior as a right attitude (CHOO; TAN, 2007).

By analogy, the scope of the Public Administration in the Agency Theory approach has one side with citizens as the principals, delegating the power for managing the assets of an entity to a third party through the democratic process, but for this purpose, the agent must commit and act in the public interest. On the other hand, the agent begins to violate the trust responsibility and intentionally break the contracts for their own benefit or that of others. That is due to the level of complexity of the administrative structure, of access to privileged information by the agent, of the governance system failures that create an atmosphere of informational asymmetry, added to the conflict of interest between principal and agent.

\subsection{TRANSPARENCY AND CURBING CORRUPTION}

The electronic disclosure has a positive impact on reducing corruption, which is also reduced by the political stability of a government (SHIM; EOM, 2008). This stability coupled with upholding democracy restrain corrupt behavior, which are more easily identified in democratic societies with higher levels of transparency and accountability (SHIM; EOM, 2008). In this sense, Justice, Melitski and Smith (2006) emphasize that social participation in the budgeting process is an instrument to promote democracy, transparency and fiscal liability in the use of public resources.

Exercising accountability requires information availability and is a result of the government's performance, not limited to the requirements of the Fiscal Responsibility Law, Law of Access to Information and Transparency Act, but must go beyond in order to provide understandable information to citizens (RAUPP; PINHO, 2013). Agostineto and Raupp (2010) noticed a growth in the use of electronic tools when publishing accountability, which facilitates monitoring the actions of public officials by society.

Information access and monitoring capacity by citizens through the use of information and communication technologies (ICT), that are linked to a legal obligation to implement an electronic government, leads to a process of promoting transparency and with this, have a more economical alternative to curb corruption (BERLOT; JAEGER; GRIMES, 2010; KOLSTAD; WIIG, 2009).

Kierkegaard (2009) asserts that information availability is the democracy and administration base and allow society to participate in politics' decision process that affects their lives. Besides that, the author reveals that an open public management awakens the population to a confident feeling that the government is acting on behalf of public interest. Considering the aforementioned, transparency can reduce corruption, by making corrupt acts riskier (KOSTALD; WIIG, 2009).

An example that electronic government is able to help in curbing corruption is the study conducted by Andersen (2009). The author when analyzing the behavior of corruption in 146 countries and over a period of 10 years (1996 to 2006), empirically showed that an electronic government implementation drastically reduced corruption. He showed that ICTs are useful tools to help global efforts to curb corruption, which is an obstacle for development and negatively affects efficiency, productivity, technological progress and long-term tax levels economic growth (SALINAS-JIMÉNEZ; SALINAS-JIMÉNEZ, 2007).

However, the use of information technologies is not always a guarantee of success. Berlot, Jaeger and Grimes (2010) point out that despite the positive history upon the use of technologies, there is always a risk for information manipulation or even censorship by public agents due to cultural aspects or restrictive interest. For the authors, the success of the technological initiatives is based on factors such as the effective implementation of 
BBR

technology and broad access, education, culture and acceptance by the population, that involve a maturation and social development process in a longer period of time. Kolstad and Wiig (2009) emphasize that besides information access, it is necessary to have available sources for information process and incentive to act upon its processed information.

Kolstad and Wiig (2009) reported that transparency role in reducing corruption is misunderstood, because it increases corruption. Authors pointed that excess of transparency could reveal who the most relevant agents are and could be target contacts with the goal being harassed for obtaining unfair advantage from bribers, increasing the degree of corruption. On the other hand, the positive impact of transparency depends on the level of education of the electorate, the degree of power that stakeholders have in holding a government accountable, and the collective or private nature on which the information is provided.

In the field of Public Administration, few studies address the relationship between public financial management data and transparency standards and the consequent implications on the judgment of accounts. Judgment upon irregularities could be due to mistakes or the indication of fraud or even the confirmation of corruption. Besides that, the study seeks to contribute to reducing the lack of studies that focus on frauds detection methods (DORMINEY et al., 2012). This study aims to fill the gap in the literature and to verify whether there is an adherence between the level of municipal transparency and the model of Benford's Law, in the process of municipal public expenditure execution.

\section{RESEARCH METHODOLOGY}

This study may be characterized as an exploratory research. Exploratory research aims to bring an overview on a particular subject, yet poorly explored, clarifying and simultaneously encouraging future studies through more systematic procedures (GIL, 2012).

The research on the application of Benford's Law in the context of accounting and auditing evolved over the last 20 years. However, the association between the disclosure of public and municipal transparency expenditure is still a relatively unexplored field by researchers. Questions such as: "Does a municipality with a greater transparency index have a higher correspondence with Benford's Law?" have not yet been answered. That is why this study is inserted into exploratory research.

Benford's Law was originally described by the astronomer and Canadian-American mathematician Simon Newcomb, in 1881, when he realized that the logarithm boards had greater wear in the former than in the latter pages, i.e., the frequency of use decreased as the numbers approached nine. Thus, Newcomb (1881) succeeded in establishing a probability of occurrence ratio of the first and second digits associated with the use of the logarithm table.

Table 1 shows the probability distribution for the occurrence of the first and second digit verified by Newcomb.

Newcomb's study remained in oblivion for several years until being rediscovered by the American physicist and electrical engineer Frank Benford (1938), who generalized the studies on the likelihood of digits for several other applications such as molecular weight, length of rivers, the population of the United States, mortality rates.

Benford reached the same conclusion as Newcomb, that people generally seek numbers of lower than higher digits (DURTSCHI; HILLISON; PACINI, 2004). Durtschi, Hillison and Pacini (2004) highlight that Benford's Law is already part of several audit software due to its utility, among which $A C L^{\circledR}$ and CaseWare ${ }^{\circledR}$. It assists the detection of possible errors, fraud and other irregularities, and acts as an analytical tool for the audit planning phase. 
Table 1. Likelihood of occurrence of the first and second digit

\begin{tabular}{lcccccccccc}
\hline Digit & 0 & 1 & 2 & 3 & 4 & 5 & 6 & 7 & 8 & 9 \\
\hline $1^{\text {st }}$ Digit & $\ldots$ & $30.10 \%$ & $17.61 \%$ & $12.49 \%$ & $9.69 \%$ & $7.92 \%$ & $6.69 \%$ & $5.80 \%$ & $5.12 \%$ & $4.58 \%$ \\
$2^{\text {nd }}$ Digit & $11.97 \%$ & $11.39 \%$ & $10.88 \%$ & $10.43 \%$ & $10.03 \%$ & $9.67 \%$ & $9.34 \%$ & $9.04 \%$ & $8.76 \%$ & $8.50 \%$ \\
\hline
\end{tabular}

Source: Adapted from Newcomb (1881).

Benford's analysis gained prominence due to its broad repercussion consequent of its wide application. From that point, several studies have been carried out with the digit likelihood model. The inclusion of false data in databases was analyzed in the area of Information Technology (DEBRECENY; GRAY, 2010) and this analysis was associated to the falsification of images and documents (USTUBIOGLU, 2016). In the field of statistics, anomalies were identified in China's GDP, which could indicate a manipulation of values (HOLS, 2014). Benford's law indicated possible manipulations of air quality statistics in Beijing (STOERK, 2016). Leeman and Bochsler (2014) adopted the model to detect election fraud.

The first study applying Benford's Law in the field of Accounting bibliometrics and auditing, according to Costa, Santos and Travassos (2013), was Carslaw's, who compared the expected frequency of the first digit of the Ordinary Income with the Net Income of 220 companies with shares traded in New Zealand.

Other studies have also been observed in auditing. Nigrini (2005), for example, identified using Benford's Law, the manipulation of revenue values and earnings per share in the financial reports of 2001 and 2002 of Enron, giving rise to its bankruptcy. Cunha and Bugarin (2015) used Benford's Law as a public works audit tool, and analyzed contracts to renovate the Maracanã Soccer Stadium for the 2014 World and detected the incidence of overcharging.

The Z-test and chi-square test (Chi-square) are among the most used to verify compliance with Benford's Law (NIGRINI, 2012). Costa, Santos and Travassos (2012), Santos, Tenório and Silva (2003) and Santos et al. (2009) also adopted a methodology similar to Carslaw (1988) regarding the use of the $\mathrm{Z}$ and chi-square statistical tests.

The $\mathrm{Z}$ and chi-square tests are statistically more significant and practical to issue conclusions in auditing activities, especially when applied to a large volume of data (KRAKAR; ZGELA, 2009).

The study object of this study is public expenditure and the theme is Benford's Law and municipal transparency. Therefore, we used two sources of secondary information to conduct the study: National Transparency Ranking of the Federal Public Ministry (FPM) and transparency portals of selected municipalities.

We used the most recent National Transparency Ranking for the municipalities of Goiás, developed by the FPM (MPF, 2016), result of the second national assessment. The ranking was chosen based on the size of the proposal, which was of a national level and had support of national control bodies, and because of the recent results achieved by the actions promoted by the FPM. These recent actions showed an improvement in the transparency ranking by $31 \%$, according to information from the Social Observatory (OBSERVATÓRIO SOCIAL, 2016).

In this research, we chose two municipalities in the state of Goiás for exploratory and comparative purposes: one with higher and one with a lower transparency index, according to the classification published in the second assessment of the FPM. The research was limited to only two municipalities, thus the name of the municipalities was omitted to preserve the 
BBR

15,4

image of each one and not make an unfair differentiation, adopting the isonomic typology of Costa, Santos and Travassos (2012).

The municipality with greater transparency will be termed as "Municipality A" and the one with lesser transparency, "Municipality B". The first criterion for selecting the two municipalities was using the same system or the adoption of a similar system of disclosure of information of public expenditure, i.e., through the portal of transparency. This system has the potential of exporting data in spreadsheet format compatible with Microsoft Excel ${ }^{\circledR}$.

The State of Goiás has 246 municipalities, we selected two municipalities with similar characteristics: small size (population between 15,000 to 20,000 inhabitants); population growth of less than 2\%; both located outside the metropolitan region (more than $300 \mathrm{~km}$ from the Capital); economic value added at the basic price of the public administration close to 60 million BRL/year (data based on 2014). The current municipality expenses for 2014 ranging 30 to 40 million BRL; same number of schools in 2015; and human development index (HDI) classified as close to high (0.700) in the last census (2010). We obtained information about the municipalities from the Mauro Borges Institute (IMB, 2016).

The municipality with greater transparency $(+\mathrm{T})$ was ranked in the first decile (position 1 to 24 ) of the FPM classification and lower transparency (-t) in the eighth decile (position 175 to 199) due to the capacity of transparency portals in exporting the files of public expenditure.

\subsection{Data COLlection}

The FPM research was carried out in the middle of May 2016. Therefore, we selected a sample equivalent to all expenses by each of the two municipalities in the first quarter of the current year to carry out this exploratory research. In other words, we collected the sample from January 2016 considering values above 1.00 BRL, as to ensure that the first digit differed from zero and the validation of Benford's Law.

The sample of municipality " $A$ " represented a total of 1,453 expenditures in the amount of 21,291,309.23 BRL relating to three managers units. The sample of municipality "B" was 1,615 expenditures, amounting to $17,877,974.15$ BRL from five management units. For that reason, this study considers for the two municipalities a total of 3,068 expenditures in the amount of 39,169,283.38 BRL, i.e., slightly less than 40 million BRL. We extracted the data from the transparency websites of each municipality into electronic spreadsheets to use the Microsoft Excel ${ }^{\circledR}$ software.

\subsection{STATISTICAL MODEL}

We applied the Z-statistics or Z-test and chi-square test or $\chi^{2}$-test in this study using the model by Nigrini (2012), which is similar to the model by Carslaw (1988), Costa et al. (2012), Santos et al. (2003) and Santos et al. (2009). Therefore, we adopted the hypothesis tests to detect probability distribution differences in the Z-test (1) and chi-squared test (2 and 3) to analyze the probability expected distribution and the observed probability in accordance with Benford's Law, according to the following equations:

$$
Z=\frac{\left|p_{o}-p_{e}\right|-\frac{1}{2 n}}{\sqrt{\frac{p_{o}\left(1-p_{e}\right)}{n}}}
$$


where $p_{o}$ is the observed probability; obtained through the division between the observed frequency for each digit by the number of observations; $p_{e}$ is the expected probability, correspondent to the probability of occurrence forecasted in Benford's Law; $n$ is the number of observations; $1 / 2 \mathrm{n}$ is the continuity correction term and is only used when it is lower than $\left|p_{o}-p_{e}\right|$. A significance level of $\alpha=0.05$, as adopted with a $Z_{\text {critical }}=1.96$, adapted from Costa et al. (2012).

$$
\begin{aligned}
& \chi^{2}=\sum_{d=1}^{9} \frac{\left[p_{0}(d)-p_{e}(d)\right]^{2}}{p_{e}(d)}, \text { applied to the first digit } \\
& \chi^{2}=\sum_{d=0}^{9} \frac{\left[p_{0}(d)-p_{e}(d)\right]^{2}}{p_{e}(d)}, \text { applied to the second digit }
\end{aligned}
$$

where $p_{o}(d)$ is the observed proportion and $p_{e}(d)$ is the expected proportion, defined by: $p_{o}(d)=()$, where $p_{o}(d)$ and $f_{o}$ vary according to each digit: first or second, from 1 to 9 or 0 to 9 , respectively, $p_{e}(d)$ is the proportion of each digit, according to Benford's Law (Table 1).

Complementary, expected frequency $\left(f_{e}\right)$ is obtained through the multiplication from the expected proportion $p_{e}(d)$ by the total observations $(n)$. For example, consider that 424 is the observed frequency $\left(f_{o}\right)$ from the first digit, with this digit being 1 . Also, consider that the total of observations are 1,453 . Thus, the observed proportion $p_{o}(d)$ corresponds to $0.291(424 / 1,453)$ and the expected proportion $p_{e}(d)$ according to Benford's Law is 0.301 (Table 1).

Equation (2) is used for first digit and equation (3) for the other positions. A significance level of $\alpha=0.05$, as adopted, for a degree of freedom 8 (first Digit) and 9 (second Digit) obtaining critical chi-squared values of 15.507 and 16.919, adapted from Costa, Santos and Travassos (2012) and Santos, Diniz and Corrar (2005).

Because of the problem posed in this study, we established the following assumptions established for the distribution, considering the Z-test:

\section{Z-test for the first digit:}

$\mathrm{H}_{0 \mathrm{~A}}$ : there is no risk of irregularities in the municipal public expenditure

$\mathrm{H}_{1 \mathrm{~A}}$ : there is risk of irregularities in the municipal public expenditure

\section{Z-test for the second digit:}

$\mathrm{H}_{0 \mathrm{~B}}$ : there is no risk of irregularities in the municipal public expenditure

$\mathrm{H}_{1 \mathrm{~B}}$ : there is risk of irregularities in the municipal public expenditure

The following hypotheses were established for the chi-square test:

\section{Chi-squared test for the first digit:}

$\mathrm{H}_{\mathrm{oC}}$ : there is no risk of irregularities in the municipal public expenditure

$\mathrm{H}_{1 \mathrm{C}}$ : there is risk of irregularities in the municipal public expenditure

\section{Chi-squared test for the second digit:}

$\mathrm{H}_{\mathrm{OD}}$ : there is no risk of irregularities in the municipal public expenditure

$\mathrm{H}_{1 \mathrm{D}}$ : there is risk of irregularities in the municipal public expenditure. 
BBR

15,4

According to Nigrini (2012), the Z-test itself does not match the whole-digit analysis to achieve an idea of the general extent of non-compliance. We cannot add or combine the Z-statistics in any way to get an idea of the overall extent of nonconformity. The author considers, an extension to the Z-statistic is a combined test for the digits using either the chi-square or the Kolmogorov-Smirnov (KS) tests.

Considering that chi-squared test is used more than the KS test for Benford's Law application in audit scope and in research about frauds, we chose chi-squared. As examples of choice, studies conducted by Santos, Diniz and Corrar (2005), Nigrini (2005), Nigrini (2005), Costa, Santos and Travassos (2012), Krakar and Zgela (2009) and Silva, Travassos and Costa (2017) can be mentioned.

\section{RESULTS AND DISCUSSION}

In this section the data on expenditure contracts in the municipalities " $\mathrm{A}$ " and " $\mathrm{B}$ " consisting of the first quarter of 2016 (January to April) will be presented and analyzed. The contracts considered in this study are represented in Table 2:

Table 2. Expenditure contracts analyzed in both municipalities

\begin{tabular}{lcc}
\hline Item & Municipality A $(+\mathrm{T})$ & Municipality B (-t) \\
\hline MU (n) & 3 & 5 \\
Contracts (n) & 1,453 & 1,615 \\
Total (BRL) & $21,291,309.23$ & $17,877,974.15$ \\
Minimum (BRL) & 4.00 & 1.02 \\
Maximum (BRL) & $1,533,291.30$ & $615,000.00$ \\
Mean (BRL) & $14,653.34$ & $11,069.95$
\end{tabular}

Where: MU (n) is the number of Management Units in the municipality; $(+\mathrm{T})$ corresponds to the most transparent municipality; (-t) corresponds to the less transparent municipality; Contracts (n) corresponds to the number of contracts that is also the number of observations considered for each municipality. Total is the sum from all contracts considering the research period in each municipality; Minimum corresponds to the lowest contracted value by the municipality considering the research period; Maximum corresponds to the highest contracted value by the municipality considering the research; Mean corresponds to the average contracts in each municipality. Source: Research data.

\subsection{ANALYSis OF THE EXPENDITURE OF MUNICIPALITY " ${ }^{69}(+\mathrm{T})$}

Data regarding the analysis of the first digit the values of the expenses in Municipality "A" are shown in Table 3.

We identified a discrepancy in regards to Benford's Law in contracts issued with monetary value with the numbers 2 and 6 considering the application of the Z-test for the first digit (Table 3). The statistical measure $Z$ was higher than the critical value (1.96) for both numbers ( 2 and 6 ). The chi-squared test applied to the overall figures revealed a value of 33.500, which is higher than the critical one. This reveals that the contracts in their total value do not conform to Benford's Law, that suggests the decision to reject hypothesis $\mathrm{H}_{0 \mathrm{~A}}$ and $\mathrm{H}_{0 \mathrm{C}}$. Therefore, these contracts issued (with greater risk of irregularities) should be assessed with caution given the complete disagreement with Benford's Law and that there was individual divergence in the numbers 2 and 6 .

The second test conducted at municipality " $A$ " regarded the second digit of the expenditure values, as shown in Table 4.

The application of the Z-test for the second digit indicated discrepancy from Benford's Law issued in relation to contracts with monetary values with the numbers $0,4,7$ and 8 
Table 3. Test for the $1^{\text {st }}$ digit of Municipality “ $A$ ” $(+T)$

\begin{tabular}{|c|c|c|c|c|c|c|c|c|c|}
\hline \multirow{2}{*}{$1^{\text {st }}$ Digit } & \multirow{2}{*}{ Freq. } & \multirow{2}{*}{$\mathrm{p}_{\mathrm{o}}$} & $\mathrm{BL}$ & \multirow{2}{*}{$\mathrm{p}_{\mathrm{o}}-\mathrm{p}_{\mathrm{e}}$} & \multirow{2}{*}{$\mathrm{f}_{\mathrm{o}}$} & \multirow{2}{*}{$\mathrm{f}_{\mathrm{e}}$} & \multirow{2}{*}{$\begin{array}{c}\operatorname{dif} \\
\left(f_{o}-f_{e}\right)\end{array}$} & \multirow{2}{*}{ Z } & \multirow{2}{*}{$\chi^{2}$} \\
\hline & & & $\mathrm{p}_{\mathrm{e}}$ & & & & & & \\
\hline 1 & 424 & 0.291 & 0.301 & -0.009 & 424 & 437 & -13 & 0.735 & 0.408 \\
\hline 2 & 226 & 0.155 & 0.176 & -0.020 & 226 & 256 & -30 & 2.013 & 3.456 \\
\hline 3 & 179 & 0.123 & 0.125 & -0.002 & 179 & 182 & -3 & 0.169 & 0.038 \\
\hline 4 & 134 & 0.092 & 0.097 & -0.005 & 134 & 141 & -7 & 0.571 & 0.342 \\
\hline 5 & 112 & 0.077 & 0.079 & -0.002 & 112 & 115 & -3 & 0.222 & 0.068 \\
\hline 6 & 144 & 0.099 & 0.067 & 0.032 & 144 & 97 & 47 & 4.842 & 22.353 \\
\hline 7 & 96 & 0.066 & 0.058 & 0.008 & 96 & 84 & 12 & 1.260 & 1.632 \\
\hline 8 & 86 & 0.059 & 0.051 & 0.008 & 86 & 74 & 12 & 1.359 & 1.910 \\
\hline 9 & 52 & 0.035 & 0.046 & -0.010 & 52 & 67 & -15 & 1.796 & 3.294 \\
\hline Total & 1,453 & 1 & 1 & 0 & 1,453 & 1,453 & 0 & - & 33.500 \\
\hline
\end{tabular}

Where: $1^{\text {st }}$ Digit is the first digit of the monetary value of the contract; Freq. is the frequency of first digit in high transparent municipality contracts issued $(+\mathrm{T})$ considering the studied period; $p$ is the observed probability; $p_{e}$ is the expected probability according to Benford's Law; $p_{o}-p_{e}$ is the difference between the observed and expected probability; $f$ is the observed frequency; $f$ is the expected frequency; dif is the difference between the observed frequency $\left(f_{o}\right)$ and the expected frequency $\left(f_{e}\right) ; \mathrm{Z}$ is the $\mathrm{Z}$-test and $\chi^{2}$ is the chi-squared test. Critical values for $\mathrm{Z}$ and $\chi^{2}$ correspond to 1.96 and 15.507 , respectively. $n$ value is equal to 1,453 observations. Source: Research data.

Table 4. Test for the $2^{\text {nd }}$ digit of Municipality "A" $(+T)$.

\begin{tabular}{|c|c|c|c|c|c|c|c|c|c|}
\hline $2^{\text {nd }}$ Digit & Freq. & $\mathrm{p}_{\mathrm{o}}$ & $\begin{array}{c}\mathrm{BL} \\
\mathrm{p}_{\mathrm{e}}\end{array}$ & $p_{o}-p_{e}$ & $f_{o}$ & $f_{e}$ & $\begin{array}{c}\operatorname{dif} \\
\left(f_{o}-f_{e}\right)\end{array}$ & $\mathrm{Z}$ & $\chi^{2}$ \\
\hline 0 & 315 & 0.217 & 0.120 & 0.097 & 315 & 174 & 141 & 11.364 & 114.498 \\
\hline 1 & 142 & 0.098 & 0.114 & -0.016 & 142 & 165 & -23 & 1.898 & 3.332 \\
\hline 2 & 151 & 0.104 & 0.109 & -0.005 & 151 & 158 & -7 & 0.557 & 0.320 \\
\hline 3 & 153 & 0.105 & 0.104 & 0.001 & 153 & 152 & 1 & 0.078 & 0.013 \\
\hline 4 & 114 & 0.078 & 0.100 & -0.022 & 114 & 146 & -32 & 2.729 & 6.917 \\
\hline 5 & 132 & 0.091 & 0.097 & -0.006 & 132 & 140 & -8 & 0.708 & 0.511 \\
\hline 6 & 123 & 0.085 & 0.093 & -0.009 & 123 & 136 & -13 & 1.097 & 1.183 \\
\hline 7 & 92 & 0.063 & 0.090 & -0.027 & 92 & 131 & -39 & 3.549 & 11.752 \\
\hline 8 & 103 & 0.071 & 0.088 & -0.017 & 103 & 127 & -24 & 2.203 & 4.618 \\
\hline 9 & 128 & 0.088 & 0.085 & 0.003 & 128 & 124 & 4 & 0.376 & 0.164 \\
\hline Total & 1,453 & 1 & 1 & 0 & 1,453 & 1,453 & 0 & - & 143.307 \\
\hline
\end{tabular}

Where: $2^{\text {nd }}$ Digit is the second digit of the monetary value of the contract; Freq. is the frequency of occurrence of the second digit in contracts of the municipality with greater transparency $(+T)$ in the considered period; $p$ is the observed probability; $p$ is the expected probability according to Benford's Law; $p_{o}-p_{e}$ is the difference between the observed probability and the expected probability; $f_{o}$ is the observed frequency; $f_{\rho}$ is the expected frequency; dif is the difference between observed frequency $\left(f_{o}\right)$ and the expected frequency $\left(f_{e}\right) ; \mathrm{Z}$ is the $\mathrm{Z}$-test and $\chi^{2}$ is the chi-squared test. The critical values for the Z-test and $\chi^{2}$ correspond to 1.96 and 16.919, respectively. The value of $n$ equals 1,453 observations. Source: Research data. 
BBR

15,4

for the second digit. The statistical measure $Z$ was above the critical value (1.96) for the digits $0,4,7$ and 8 . For this number, the chi-squared test showed a result of 143.307, which is higher than the critical value. Considering the results from $\mathrm{Z}$ and chi-squared tests, we rejected the $\mathrm{H}_{0 \mathrm{~B}}$ and $\mathrm{H}_{0 \mathrm{D}}$ hypotheses. This reveals that the contracts in their total value do not conform to the established by Benford's Law. Hence, one red flag is evidenced, considering that they are entirely untrue to Benford's Law and that there was individual divergence in the individual sayings $0,4,7$ and 8 .

\subsection{ANALYSiS OF THE EXPENDITURE OF MUNiCIPALITY B (-T)}

Data regarding the analysis of the first digit the values of the expenses in Municipality "B" are shown in Table 5:

Table 5. Test for the $1^{\text {st }}$ digit of Municipality “B” (-t)

\begin{tabular}{|c|c|c|c|c|c|c|c|c|c|}
\hline \multirow{2}{*}{$1^{\text {st }}$ Digit } & \multirow{2}{*}{ Freq. } & \multirow{2}{*}{$\mathrm{p}_{\mathrm{o}}$} & BL & \multirow{2}{*}{$\mathrm{p}_{\mathrm{o}}-\mathrm{p}_{\mathrm{e}}$} & \multirow{2}{*}{$f_{o}$} & \multirow{2}{*}{$\mathrm{f}_{\mathrm{e}}$} & \multirow{2}{*}{$\begin{array}{c}\operatorname{dif} \\
\left(f_{o}-f_{e}\right)\end{array}$} & \multirow{2}{*}{ Z } & \multirow{2}{*}{$\chi^{2}$} \\
\hline & & & $\mathrm{p}_{\mathrm{e}}$ & & & & & & \\
\hline 1 & 533 & 0.330 & 0.301 & 0.029 & 533 & 486 & 47 & 2.516 & 4.522 \\
\hline 2 & 262 & 0.162 & 0.176 & -0.014 & 262 & 284 & -22 & 1.421 & 1.740 \\
\hline 3 & 138 & 0.085 & 0.125 & -0.040 & 138 & 202 & -64 & 4.768 & 20.211 \\
\hline 4 & 175 & 0.108 & 0.097 & 0.011 & 175 & 157 & 18 & 1.500 & 2.148 \\
\hline 5 & 162 & 0.100 & 0.079 & 0.021 & 162 & 128 & 34 & 3.129 & 9.283 \\
\hline 6 & 82 & 0.050 & 0.067 & -0.016 & 82 & 108 & -26 & 2.558 & 6.346 \\
\hline 7 & 75 & 0.046 & 0.058 & -0.012 & 75 & 94 & -19 & 1.934 & 3.721 \\
\hline 8 & 76 & 0.047 & 0.051 & -0.004 & 76 & 82 & -6 & 0.663 & 0.492 \\
\hline 9 & 112 & 0.069 & 0.046 & 0.023 & 112 & 74 & 38 & 4.420 & 19.142 \\
\hline Total & 1,615 & 1 & 1 & 0 & 1,615 & 1,615 & 0 & - & 67.605 \\
\hline
\end{tabular}

Where: $1^{s t}$ Digit is the first digit of the monetary value of the contract; Freq. is the frequency of occurrence of the first digit in contracts of the municipality with less transparency $(-t)$ in the considered period; $p_{o}$ is the observed probability; $p_{e}$ is the expected probability according to Benford's Law; $p_{o}-p_{e}$ is the difference between the observed probability and the expected probability; $f_{o}$ is the observed frequency; $f_{e}$ is the expected frequency; dif is the difference between observed frequency $\left(f_{o}\right)$ and the expected frequency $\left(f_{e}\right) ; \mathrm{Z}$ is the Z-test and $\chi^{2}$ is the chi-squared test. The critical values for the $Z$-test and $\chi^{2}$ correspond to 1.96 and 15.507 , respectively. The value of $n$ equals 1,615 observations. Source: Research data.

The application of the Z-test for the first digit showed a discrepancy regarding Benford's Law for contracts issued with monetary value with the numbers 1, 3, 5, 6 and 9 (Table 5). The statistical measure $Z$ was above the critical value (1.96) for the numbers 1, 3, 5, 6 and 9. The chi-squared test calculated resulted on 67,605 , which is higher than the critical value. Denotes that the total expenditures are not in accordance with Benford's Law, so considering the Z-test and chi-squared test, it suggests the rejection of hypothesis $\mathrm{H}_{0 \mathrm{~A}}$ and $\mathrm{H}_{0 \mathrm{C}}$.

We need to pay special attention when analyzing these contracts issued, which have a higher likelihood of being irregular, considering that the expenses are entirely untrue to Benford's Law and that there was individual divergence in the individual numbers $1,3,5$, 6 and 9.

Table 6 shows the other test carried out, regarding the second digit of the expenditure of municipality "B".

The tests of the first digit had shown disagreements regarding Benford's Law in Municipality "B". The test of the second digit set forth in Table 6 further exacerbates the differences. 
Table 6. Test of the $2^{\text {nd }}$ digit for Municipality " $B$ " (-t)

\begin{tabular}{|c|c|c|c|c|c|c|c|c|c|}
\hline \multirow{2}{*}{$2^{\text {nd }}$ Digit } & \multirow{2}{*}{ Freq. } & \multirow{2}{*}{$\mathrm{p}_{\mathrm{o}}$} & $\mathrm{BL}$ & \multirow{2}{*}{$\mathrm{p}_{\mathrm{o}}-\mathrm{p}_{\mathrm{e}}$} & \multirow{2}{*}{$\mathrm{f}_{\mathrm{o}}$} & \multirow{2}{*}{$\mathrm{f}_{\mathrm{e}}$} & \multirow{2}{*}{$\begin{array}{c}\operatorname{dif} \\
\left(f_{o}-f_{e}\right)\end{array}$} & \multirow{2}{*}{ Z } & \multirow{2}{*}{$\chi^{2}$} \\
\hline & & & $\mathrm{p}_{\mathrm{e}}$ & & & & & & \\
\hline 0 & 399 & 0.2471 & 0.1197 & 0.127 & 399 & 193 & 206 & 15.732 & 218.950 \\
\hline 1 & 109 & 0.0675 & 0.1139 & -0.046 & 110 & 184 & -75 & 5.830 & 30.527 \\
\hline 2 & 206 & 0.1276 & 0.1088 & 0.019 & 206 & 176 & 30 & 2.378 & 5.209 \\
\hline 3 & 126 & 0.0780 & 0.1043 & -0.026 & 126 & 168 & -42 & 3.418 & 10.716 \\
\hline 4 & 118 & 0.0731 & 0.1003 & -0.027 & 118 & 162 & -44 & 3.603 & 11.951 \\
\hline 5 & 202 & 0.1251 & 0.0967 & 0.028 & 202 & 156 & 46 & 3.820 & 13.471 \\
\hline 6 & 101 & 0.0625 & 0.0934 & -0.031 & 101 & 151 & -50 & 4.216 & 16.442 \\
\hline 7 & 130 & 0.0805 & 0.0904 & -0.010 & 130 & 146 & -16 & 1.338 & 1.736 \\
\hline 8 & 114 & 0.0706 & 0.0876 & -0.017 & 114 & 141 & -27 & 2.370 & 5.318 \\
\hline 9 & 110 & 0.0681 & 0.0850 & -0.017 & 110 & 137 & -27 & 2.389 & 5.419 \\
\hline Total & 1,615 & 1 & 1 & 0 & 1,615 & 1,615 & 0 & & 319.739 \\
\hline
\end{tabular}

Where: $2^{\text {nd }}$ Digit is the second digit of the monetary value of the contract; Freq. is the frequency of occurrence of the second digit in contracts of the municipality with less transparency $(-t)$ in the considered period; $p$ is the observed probability; $p$ is the expected probability according to Benford's Law; $p_{o}-p_{e}$ is the difference between the observed probability and the expected probability; $f_{o}$ is the observed frequency; $f$ is the expected frequency; dif is the difference between the observed frequency $\left(f_{o}\right)$ and the expected frequency $\left(f_{e}\right) ; \mathrm{Z}$ is the Z-test and $\chi^{2}$ is the chi-squared test. The critical values for the Z-test and $\chi^{2}$ correspond to 1.96 and 16.919 , respectively. The value of $n$ is equal to 1,615 observations. Source: Research data.

The Z-test for the second digit pointed out discrepancies in relation to Benford's Law for contracts issued with monetary value of numbers $0,1,2,3,4,5,6,8$ and 9 , in other words, only number 7 showed no significant differences. The Z-test was above the critical value (1.96) for the numbers $0,1,2,3,4,5,6,8$ and 9. In turn, the chi-squared test calculated for the second digit also showed a higher value than the critical one. Therefore, according to the Z-test and chi-squared we suggest the rejection of hypothesis $\mathrm{H}_{0 \mathrm{~B}}$ and $\mathrm{H}_{0 \mathrm{D}}$. There is no compliance with Benford's Law considering the total value of contracts issued, mainly due to the influence of the discrepancy in the number 0 (chi-squared test $=218.950$ ).

The individual unconformity of the chi-squared values for the numbers $0,1,2,3,4,5,6$, 8,9 and total, is a strong indication as to whether the contracts issued exhibited irregularities with regard to Benford's Law. However, the test of the second digit points out problems in most expenses, which may limit the analysis of the audit because of the large sample size, because nine of the ten digits present problems.

\subsection{Summary data Set OF The Two Municipalities}

The digits that did not conform the Benford's Law, after the $\mathrm{Z}$ and chi-squared tests are shown in Table 7.

The rejection of the null hypothesis for the global value of contracts issued by the two municipalities is evident, as the calculated chi-square is greater than for the critical value for both the first and second digits (Table 7). Thus, there are strong indications for a probability of finding irregularities in the contracts issued on both municipalities.

Municipality " $\mathrm{A}$ " $(+\mathrm{T})$ had lower quantity of digits in disagreement with Benford's Law, for the tests carried out with both the first and second digits. Municipality "B" (-t) yielded a larger number of digits inconsistent with Benford's Law in the first and second digits. Namely, five digits in disagreement in testing the first digit and nine for the second digit. 
BBR

15,4

343

Table 7. Summary of discrepancies in regards to the $Z$ and $\chi^{2}$-Tests for the Municipalities " $A$ " and " $B$ "

\begin{tabular}{cccccc}
\hline \multirow{2}{*}{ Digit } & \multicolumn{2}{c}{ Test } & \multicolumn{2}{c}{ Municipality A (+T) } & \multicolumn{2}{c}{ Municipality B (-t) } \\
& & $1^{\text {st }}$ Digit & $2^{\text {nd }}$ Digit & $1^{\text {st }}$ Digit & $2^{\text {nd }}$ Digit \\
\hline 0 & $*$ & + & $*$ & + \\
1 & - & - & + & + \\
2 & + & - & - & + \\
3 & - & - & + & + \\
4 & Z-test & - & + & - & + \\
5 & & - & - & + & + \\
6 & + & - & + & + \\
7 & - & + & - & - \\
8 & & - & + & - & + \\
9 & - & - & + & + \\
\hline
\end{tabular}

* Benford's Law does not consider the digit 0 as the first digit. Where: $(+)$ for the Z-test indicates that statistical measure exceeded the critical limit of 1.96 for each digit individually analyzed and the contracts values that begin with these digits would demand greater care due to non-conformity according to Benford's Law; (-) indicates that statistical measure resulted in a value below the critical limit of 1.96; $(+)$ for the Chi-squared test indicates that statistical measure exceeded the critical limit of 15.507 for the $1^{\text {st }}$ digit and 16.919 for the $2^{\text {nd }}$ digit, considering global values of all digits together. Source: Research data.

Concerning the discrepancy of the digits, Santos et at. (2009) evaluated the application of Benford's Law in an audit of any type of service tax (ISS) in a Northeastern State city found that the differences found for Digits 2, 7 and 8 were associated to tax evasion, i.e., the highest percentage of bills unreported to the tax authorities. The author showed that the chi-squared test was higher than the critical value $(67.409>15.507)$ and the $Z$-test for the digits 2, 7 and 8 also showed values above the critical value.

The aforementioned authors corroborate the results obtained in this study, proving with a practical application, that there is a greater likelihood of fraud or irregularities when the test results present values that exceed the critical limits. The Z-test values for the first digit were extrapolated for the numbers 2 and 6 at Municipality "A" $(+\mathrm{T})$ and 1, 3, 5, 6 and 9 at Municipality "B" $(-t)$. The evaluation of the second digit showed discrepancies for the numbers $0,4,7,8$ for Municipality " $\mathrm{A}$ " $(+\mathrm{T})$ and $0,1,2,3,4,5,6,8$ and 9 for Municipality " $B$ " (-t). It is noteworthy that both municipalities for the chi-squared test exceeded the critical value.

Nigrini (2005), evaluated the revenue and earnings per share amounts in the financial statements of Enron from 2001 and 2002, found a chi-squared value of 18.90, proving to be higher than the critical point of distribution (15.51) at a 5\% significance level. A similar pattern was recorded in this study, where the chi-squared value was also higher than the critical level for both first and second digits, for both of the municipalities analyzed.

Costa et al. (2012) observed higher deviations respectively in digits 6, 7,8 and 9, where the occurrence of digits 7 and 8 increased and digits 9 and 6 reduced, considering the predicted by Benford's Law.

Krakar and Zgela (2009) evaluated 1,745,311 financial transactions between commercial agents and financial agents of Croatia, from February to May, 2008. To do so the authors evaluated the first, second and first two digits through the chi-squared test, Z-test and Mean Absolut Deviation (MAD), and found significant deviations in the numbers 5 and 9 in the test of the first Digit, recommending a more detailed investigation of the data. 
According to Silva, Travassos and Costa (2017), the identification of discrepancies in public expenditure (public spending) through the use of Benford's Law allows the elaboration of audit tracks (pathways). The tracks, in turn, will lead the audit team to a better optimization of human resources and time for the sample selection with relevant points in the process of resource monitoring.

Table 8 displays in summary the numbers not conforming to Benford's Law, in addition to the percentage that represents the individual contracts issued with these numbers $\left(1^{\text {st }}\right.$ and $2^{\text {nd }}$ digits) relative to the sum of each municipality.

Table 8. Contracts Issued which First Digits Disagree with Benford's Law

\begin{tabular}{cccccc}
\hline \multirow{2}{*}{ Municipality } & \multicolumn{2}{c}{ Non-Conformity Digits } & Contracts (n) & $\begin{array}{c}\text { Contracts } \\
(\mathrm{R} \$)\end{array}$ & $\begin{array}{c}\% \text { Total } \\
\text { Contracts }\end{array}$ \\
\hline \multirow{2}{*}{ "A" (+T) } & $1^{\text {st }}$ Digit & 2 and 6 & 370 & $6,249,130,66$ & $29.35 \%$ \\
& $2^{\text {nd }}$ Digit & $0,4,7$ and 8 & 624 & $8,124,278,14$ & $38.16 \%$ \\
"B" (-t) & $1^{\text {st }}$ Digit & $1,3,5,6$ and 9 & 1027 & $11,332,636,55$ & $63.39 \%$ \\
& $2^{\text {nd }}$ Digit & $0,1,2,3,4,5,6,8$ and 9 & 1485 & $16,324,302,51$ & $91.31 \%$ \\
\hline
\end{tabular}

Where: "A" $(+\mathrm{T})$ is the municipality with greater transparency; "B" $(-\mathrm{t})$ is the municipality with less transparency; Digit not conforming correspond to the number of digits (first or second) of contracts issued at value that did not conform to Benford's Law, considering the Z-test (Table 7); Contracts $(n)$ is the number of contracts issued in each municipality in disagreement with Benford's Law; Contracts (BRL) is the sum of values of contracts issued for each digit in disagreement with Benford's Law; \% Total Contracts is the percentage in relation to the total values of contracts issued per municipality in the period of the survey. ${ }^{1}$ In municipality "A" the total of contracts issued was $21,291,309.23 \mathrm{BRL}$, corresponding to 1,453 observations. In municipality "B" the total of contracts issued was 17,877,974.15 BRL, corresponding to 1,615 observations according to Table 2. Source: Research data.

Municipality " $\mathrm{B}$ " (-t) has more numbers in disagreement with Benford's Law than Municipality "A" $(+\mathrm{T})$, for both $1^{\text {st }}$ and $2^{\text {nd }}$ digits (Table 8$)$. Disparity between the two municipalities is even more conspicuous regarding the number of contracts issued in each municipality. The numbers in disagreement in Municipality " $B$ " (-t) (1, 3, 5, 6 and 9), considering the Z-Test for the first digit represented $63.39 \%$ of the total contracts issued. The disagreement of numbers 2 and 6 observed for Municipality "A" (+T) represented $29.35 \%$ of issued contracts.

The disparity between the two municipalities increases further when applying the Z-test in the second digit of contracts values. The numbers in disagreement in Municipality " $B$ " $(-t)(0,1,2,3,4,5,6,8$ and 9$)$ represented $91.31 \%$ of the total contracts issued in this same municipality. In turn, the inconsistency of the numbers $0,4,7,8$ in Municipality " $A$ " (+T) corresponds to $38.16 \%$ of issued contracts.

Cunha and Bugarin (2015) identified an overbilling of 41,601,247.32 BRL in the first digits 11 and 25 of the individual costs of the services, representing $27.74 \%$ of the total overprice determined in the audit of the Federal Audit Court. In the present study, nonconformities in the Benford relationship were found for $29.35 \%$ and $63.39 \%$ of total issued contracts in Municipalities " $\mathrm{A}$ " and " $\mathrm{B}$ ", respectively, for the first digit and $38.16 \%$ and $91.31 \%$ for the second digit.

As well as based on economic theory, some contracts in public administration with political agents also show imperfections, because they do not show bonuses clauses considering the assumed risk. For this purpose, it could improve asymmetrical information (HOLMSTRON, 1979), and also influenced by agent behavior (BAKER et al., 1988), that has access to superior information (LAMBERT, 2007) would manage transparency level to 
BBR

15,4

hide the action that targets its personal opportunist interest, instead of the public interest. If, in a further moment, a documental analysis would prove the fraud linked to divergences reported based on BL, agent behavior should be explained through the "fraud triangle" proposed by Cressey (1953), which links the opportunity, the pressure and rationalization.

\section{CONCLUSION AND FINAL CONSIDERATIONS}

Given the above, Municipality "A", the one with the highest transparency $(+T)$, has greater conformity with Benford's Law when compared with Municipality "B", with lower transparency (-t). Likewise, Municipality "B" (-t) showed a greater discrepancy between the observed frequencies and the expected frequencies. Consequently, the volume of funds to be subject to an audit is higher in Municipality "B" $(-t)$ than Municipality " $A$ " $(+T)$.

Therefore, for this case, Municipality " $B$ " (-t) has a higher likelihood of having expenditure irregularities, based on Benford's Law, that is, its risk is higher.

In any event, we identified discrepancies in the first and second digits through the application of Benford's Law for both municipalities, differing only by the magnitude of unconformities.

A justification would be the possibility of irregularities in the management of the year 2016, due to the adopted procedures in the year 2015. In the case of Municipality "B" (-t), the previous opinion from the Court of Accounts about government accounts for 2015 was their rejection, imposing a fine for the political agent. For Municipality " $A$ " $(+t)$, the judgment done by the Court of Accounts was for the approval with a reserve and a fine.

The accounts judgment reflects a position in the transparency ranking and could be a possible indicative for conformity or not when related to Benford's Law. For 2016, government accounts were not yet analyzed. Another explanation would be the exacerbated opportunistic behavior from the public agent due to failures in public administration contracts, which does not balance the risk/responsibility with monetary compensation.

Benford's Law may also be used for a previous analysis of municipal public expenditure, to direct future audits, and serve as one of the variables to measure the degree of transparency of a municipality.

Future studies should focus on building transparency indexes with the inclusion of "conformity with Benford's Law" as a model variable, as well as increasing the number of municipalities studied.

The research sought to analyze the municipal transparency using the municipal websites as reference and found a limitation on data availability, because of the wide variety of tools that do not enable the exporting of data in the same format. The existence of a national standardization or a single site of transparency of municipal expenditure on a national level would facilitate the access to information and broaden social control.

\section{ACKNOWLEDGEMENTS}

The authors want to thank the contribution done by the editor from the Brazilian Business Review, Bruno Funchal, for his useful and constructive suggestions aiming at the improvement of this paper and two anonymous reviewers for their comments.

\section{REFERENCES}

AGOSTINETO, R. C.; RAUPP, F. M. Prestação de contas por meio de portais eletrônicos: um estudo em câmaras municipais da grande Florianópolis. Revista Universo Contábil, p. 64-79, 2010.

AKERLOF, G. The Market for "Lemons": Quality Uncertainty and the Market Mechanism. The Quarterly Journal of Economics, v. 84, n. 3, p. 488-500, 1970. 
ANDERSEN, T. B. E-Government as an anti-corruption strategy. Information Economics and Policy, v. 21, n. 3, p. 201-210, 2009.

BAKER, G. P.; JENSEN, M. C.; MURPHY, K. J. Compensation and incentives: practice vs. theory. The Journal of Finance. 1988. v. 43, n. 3, p. 593.

BENFORD, F. The Law of Anomalous Numbers. American Philosophical Society, v. 78, n. 4, p. 551-572, 1938.

BERTOT, J. C.; JAEGER, P. T.; GRIMES, J. M. Using ICTs to create a culture of transparency: E-government and social media as openness and anti-corruption tools for societies. Government Information Quarterly, v. 27, n. 3, p. 264-271, 1988.

CARSLAW, C. A. P. Anomalies in Income Numbers: Evidence of Goal Oriented Behavior. The Accounting Review, v. LXIII, n. 2, p. 321-327, 1988.

CHOO, F.; TAN, K. An "American Dream" theory of corporate executive Fraud. Accounting Forum, v. 31, n. 2, p. 203-215, 2007.

COSTA, J. I. F.; SANTOS, J.; TRAVASSOS, S. K. M. An Analysis of Federal Entities' Compliance with Public Spending: Applying the Newcomb-Benford Law to the $1^{\text {st }}$ and $2^{\text {nd }}$ Digits of Spending in Two Brazilian States. Revista Contabilidade \& Finanças, v. 23, n. 60, p. 187-198, 2012.

COSTA, J. I. DE F.; TRAVASSOS, S. K. DE M.; SANTOS, J. DOS. Application of Newcomb-Benford Law in Accounting Audit: a bibliometric analysis in the period from 1988 to 2011. 10th International Conference on Information Systems and Technology Management - CONTECSI. Anais...São Paulo: 2013.

CRESSEY, D. R. Other People's Money: A study in the social psychology of embezzlement. Glencoe, IL: The free press, 1953.

CUNHA, F. C.; BUGARIN, M. S. Benford's law for audit of public works: An analysis of overpricing in Maracanã soccer arena's renovation. Economics Bulletin, v. 35, n. 2, p. 1168-1176, 2015.

DEBRECENY, R. S.; GRAY, G. L. Data mining journal entries for fraud detection: An exploratory study. International Journal of Accounting Information Systems, v. 11, n. 3, p. 157-181, 2010.

DURTSCHI, C.; HILLISON, W.; PACINI, C. The Effective Use of Benford's Law to Assist in Detecting Fraud in Accounting Data. Journal of Forensic Accounting, v. 99, n. 99, p. 17-34, 2004.

FUDENBERG, D.; HOLMSTROM, B.; MILGROM, P. Short-term contracts and long-term agency relationships. Journal of Economic Theory, v. 51, n. 1, p. 1-31, 1990.

GIL, Antonio Carlos. Métodos e técnicas de pesquisa social. $6^{a}$ ed. São Paulo: Atlas, 2012.

HOLMSTROM, B. Moral hazard and observability. The Bell Journal of Economics. 1979. v. 10, n. 1, p. 74.

HOLMSTROM, B; MILGROM, P. Multitask Principal-Agent Analyses: Incentive Contracts, Asset Ownership, and Job Design. Journal of Law Economics \& Organization, v. 745, n. 18, p. 24-52, 1991.

HOLZ, C. A. The quality of China's GDP statistics. China Economic Review, v. 30, n. June 2012, p. 309-338, 2014.

IMB, INSTITUTO MAURO BORGES. Perfil Socioeconômico dos Municípios Goianos. Available at: < http://www.imb.go.gov.br/> Visited: 27 fev. 2017.

JENSEN, C.; MECKLING, H. Theory of the Firm: Managerial Behavior, Agency Costs and Ownership Structure. Journal of Financial Economics, v. 3, p. 305-360, 1976.

JUSTICE, J. B.; MELITSKI, J.; SMITH, D. L. E-Government as an Instrument of Fiscal Accountability and Responsiveness: Do the Best Practitioners Employ the Best Practices? The American Review of Public Administration, v. 36, n. 3, p. 301-322, 2006.

KIERKEGAARD, S. Open access to public documents - More secrecy, less transparency! Computer Law and Security Review, v. 25, n. 1, p. 3-27, 2009.

KOLSTAD, I.; WIIG, A. Is Transparency the Key to Reducing Corruption in Resource-Rich Countries? World Development, v. 37, n. 3, p. 521-532, 2009.

KRAKAR, Z.; ZGELA, M. Application of Benford's Law in payment systems auditing. Journal of Information and Organizational Sciences, v. 33, n. 1, p. 39-51, 2009.

LAMBERT, R. A. Agency theory and management accounting. Handbooks of management accounting research, 2006, V. 1, p. 247-268.

LEEMANN, L.; BOCHSLER, D. A systematic approach to study electoral fraud. Electoral Studies, v. 35, p. 33-47, 2014.

MPF, Ministério Público Federal. Ranking Nacional da Transparência - Resultados. Disponível em: $<$ http:// combateacorrupcao.mpf.mp.br/ranking/mapa-da-transparencia/ranking/resultados $>$. Acessado em: $31 \mathrm{de}$ julho. 2016. 
BBR

15,4

NEWCOMB, S. Note on the frequency of use of the different digits in natural numbers. American Journal of Mathematics, v. 4, n. 1, p. 39-40, 1881.

NIGRINI, M. J. An Assessment of the Change in the Incidence of Earnings Management Around the Enron-Andersen Episode. Review of Accounting and Finance, v. 4, n. 1, p. 92-110, 2005.

NIGRINI, M. J. Applications for forensic accounting, auditing, and fraud detection. John Wiley \& Sons, Inc.: Hoboken, New Jersey. 2012.

OBSERVATÓRIO SOCIAL DO BRASIL. Ranking Nacional de Transparência do MPF constata 31\% de elevação em 6 meses. Disponível em: <http://osbrasil.org.br/ranking-nacional-de-transparencia-do-mpfconstata-31-de-elevacao-em-6-meses/>. Acessado em: 31 de julho. 2016.

RAUPP, Fabiano M.; PINHO, José A. G. Accountability em câmaras municipais: uma investigação em portais eletrônicos. Revista de Administração, v.48, n.4, p. 770-782, 2013.

SALINAS-JIMÉNEZ, M. DEL M.; SALINAS-JIMÉNEZ, J. Corruption, efficiency and productivity in OECD countries. Journal of Policy Modeling, v. 29, n. 6, p. 903-915, 2007.

SANTOS, J.; DINIZ, J. A.; CORRAR, L.J. The Focus is the Sampling Theory in the Fields of Traditional Accounting Audit and Digital Audit: testing the Newcomb-Benford Law for the first digit in public accounts. BBR Brazilian Business Review, v. 2, n. 1, p. 69-86, 2005.

SANTOS, J.; TENÓRIO, J. N. B.; SILVA, L. G. C. Uma aplicação da teoria das probabilidades na Contabilometria: A Lei Newcomb-Benford como medida para análise de dados no campo da Auditoria Contábil. Contabilidade, Gestão e Governança, v. 6, n. 1, p. 35-54, 2003.

SANTOS, J. DOS et al. Aplicações da lei de Newcomb-Benford na auditoria tributária do imposto sobre serviços de qualquer natureza (ISS). Revista Contabilidade \& Finanças, v. 20, n. 49, p. 79-94, 2009.

SHIM, D. C.; EOM, T. H. E-Government and Anti-Corruption: Empirical Analysis of International Data. International Journal of Public Administration, v. 31, n. 3, p. 298-316, 2008.

SILVA, W. B.; TRAVASSOS, S. K. M.; COSTA, J. I. F. Using the Newcomb-Benford Law as a Deviation Identification Method in Continuous Auditing Environments: A Proposal for Detecting Deviations over Time. Revista Contabilidade \& Finanças, v. 28, n. 73, p. 11-26, 2017.

STOERK, T. Statistical corruption in Beijing's air quality data has likely ended in 2012. Atmospheric Environment, v. 127, p. 365-371, 2016.

USTUBIOGLU, B. et al. Anew copy move forgery detection technique with automatic threshold determination. AEU - International Journal of Electronics and Communications, v. 70, n. 8, p. 1076-1087, 2016. 